\title{
Knowledge, Attitude about Thalassemia and Sickle Cell Disease premarital screening among Saudi adults in Eastern Region, Saudi Arabia
}

\author{
Neda AlYaqoot ${ }^{1}$, Saeed AlJaberi ${ }^{1}$, Mana AlMutarid1, Abdulmohsen Al-Ghamdi ${ }^{1}$, Reem AlSayed ${ }^{1}$, Abdulaziz AlZahrani ${ }^{1}$, Haneen Al- \\ Dosari $^{1}$, Turki AlAnazi ${ }^{1}$, Farah AlZahrani ${ }^{1}$, Dania Fatani ${ }^{1}$, Omar Atean $^{1}$, Tawfeeq Naseeb ${ }^{2}$ \\ ${ }^{1}$ College of Medicine, Arabian Gulf University, Manama, Kingdom of Bahrain \\ ${ }^{2}$ Department of Family Medicine and Community Health, Arabian Gulf University, Manama, Kingdom of Bahrain \\ Correspondence should be addressed to Neda AlYaqoot College of Medicine, Arabian Gulf University, Manama, Kingdom \\ of Bahrain. Email: nalyaqoot@hotmail.com
}

Received: 13 November 2021, Revised: 23 November 2021, Accepted: 24 November 2021, Published: 8 December 20

Copyright (c) 2021 Almandili et al. This is an open access article distributed under the Creative Commons Attribution License, which permits unrestricted use, distribution, and reproduction in any medium, provided the original work is properly cited.

\begin{abstract}
Background: Hereditary diseases are caused by an abnormality in an individual's DNA, which include thalassemia and sickle cell anemia (SCD). Premarital screening is defined as testing couples who are planning to get married for common hereditary blood disorders and some infectious diseases to prevent any risk of transmitting these diseases to their spouse and children. To assess knowledge and attitude about inherited diseases (Thalassemia and SCD) in premarital screening.

Methods: This is a cross-sectional study that was conducted in the Eastern Region of Saudi Arabia at different popular malls during the month of August 2019. A convenient sample of 675 was selected randomly recruited. The questionnaire included demographic data, diseases tested in premarital screening (PMS) knowledge and attitude towards PMS.

Results: The vast majority of participants, 645 (95.6\%) thought that carrying out premarital screening is important, 651 $(96.4 \% \%)$ agreed to carry premarital screening, 551(81.6\%) participants had knowledge about the compulsory law to do PMS. Almost half of the participants agreed to take PMS for their partner's safety, furthermore, $(22.2 \%)$ agreed to do PMS to prevent transmission of hereditary diseases. Approximately half of the participants would discontinue the engagement if there is a possibility of having affected children, while $21 \%$ would base their decision on the probability of getting affected children and $14.2 \%$ would go ahead and get married. Regarding gender attitude towards possibility of having affected children; majority of females $(55.7 \%)$ and males $(44.3 \%)$ would not continue marriage.

Conclusion: There is very good knowledge about PMS, it is important to carry PMS, there is a need to increase awareness about SCD and Thalassemia to raise the number who will cancel marriage if any of these diseases are positive during PMS with the possibility of transmission to offspring.
\end{abstract}

Keywords: Premarital screening, sickle cell disease, ministry of health. 


\section{Journal of Healthcare Sciences}

\section{Introduction}

Hereditary diseases are caused by an abnormality in an individual's DNA, abnormalities can be as small as single-base mutation in just one chromosome or involve the addition or subtraction of an entire chromosome This kind of disorders include thalassemia and sickle cell anemia (SCA). Thalassemia is an inherited blood disorder characterized by low hemoglobin count and fewer red blood cells in the body, while in SCA there aren't enough healthy red blood cells to provide adequate oxygenation throughout the body. In Saudi Arabia, it has been estimated in 2017 that the total number of thalassemia and sickle cell anemia patients was 1,572140, representing 0.06\% of the entire population of Saudi Arabia, with the Eastern Region being the highest in the number of cases of SCD and Thalassemia. According to Ministry of Health (MOH) of Saudi Arabia, premarital screening is defined as a number of tests targeting those that are planning to get married for common genetic blood disorders and infectious diseases such as SCA and thalassemia, hepatitis B and hepatitis C. The premarital screening (PMS) aims to give medical consultation on the possibility of transmitting such diseases to the other partner or children and to provide the couple with an informed decision for a heathy family $(1,2)$.

A research done in Saudi Arabia between 2004 and 2009 studied the regional differences in sickle cell disease and $\beta$-thalassemia using national data. The carrier and case status of sickle cell disease and $\beta$-thalassemia were determined in couples approaching marriage between 2004 and 2009 using standard blood tests. Based on the national data from the PMS program, the prevalence of SCD was the highest in the Eastern region (134.1 per 1000), followed by Southern and Western regions (55.6 and 28.5 per 1000, respectively) and lowest in Central and Northern regions (13.7 and 13.5 per 1000 , respectively). The prevalence of $\beta$-thalassemia was highest in the Eastern region (59.0) followed by the Southern, Western and Central regions (14.2, 10.2, and 10.1 per 1000 , respectively) and was lowest in the Northern region (3.9 per 1000). There are vast differences in hemoglobinopathies among adult Saudi nationals approaching marriage, this may help policy makers better allocate resources for preventive and management programs (3). Therefore, we aim to study the knowledge, attitude and practice of the public in the Eastern region regarding SCA and $\beta$-thalassemia.

\section{Methodology}

This is a cross-sectional survey study which was conducted in the Eastern Region of Saudi Arabia at different popular malls in Dammam and Khobar. The data was collected from July 2019 until September 2019. The data collection was through a simple randomization process with a total of 675 participants included in the study. The sample was taken from the general community attending these shopping malls. A total of six malls were chosen randomly in each geographical area. Two malls from Al-Khobar area, two malls from Dhahran area and two malls from Dammam area. Participants were selected using random sampling technique by taking every third person entering the mall. We included Saudi adults $\geq 18$ years and those living in the eastern region only and excluded individuals younger than 18 years, those in healthcare sector and incomplete data.

A structured questionnaire was used to collect the data in Arabic and English. The survey consisted of questions regarding demographic data, knowledge about premarital screening, law regarding PMS, diseases screened in PMS, attitude towards PMS and decisions about it and knowledge about inheritance of Sickle Cell Disease and Thalassemia. The questions were checked in the study setting for completeness and consistency by experts in community medicine and it was statistically validated. Data management included cleaning, coding, entry, analysis and presentation in tables and graphs and a correlation testing using chi square were done by Statistical Package for Social Sciences (SPSS) version 25. The ethical approval was obtained from the Research and Ethics Committee at the College of Medicine and Medical Sciences at the Arabian Gulf University (AGU). Official permissions to conduct the study were obtained from all the selected malls. An informed oral consent was taken from the participants prior to filling the questionnaire by the researchers, explaining to them the purpose of the research. Participants were assured of the confidentiality of the information they provided.

\section{Results:}

A total of 675 participants were included in the study. Out of those, the majority were females 393 (58.2\%) and 274 (40.6\%) of the participants were between 18-27 years old. About half of the participants $(54.1 \%)$ were married while $40.7 \%$ were single and $50.8 \%$ of the population had children. Educational level of the participants varied but most of them (76.3\%) had university degree and $19.9 \%$ had only high school degree. In regard to job distribution, $47.3 \%$ were employed, $24.1 \%$ were students, $20 \%$ were unemployed and $8.6 \%$ were retired (Table1). 
Journal of Healthcare Sciences

\begin{tabular}{|c|c|c|c|}
\hline & & $\mathbf{N}$ & $\%$ \\
\hline \multirow{5}{*}{ Age group } & $18-27$ & 274 & 40.6 \\
\hline & $28-37$ & 163 & 24.1 \\
\hline & $38-47$ & 110 & 16.3 \\
\hline & $>48$ & 128 & 19 \\
\hline & Total & 675 & 100 \\
\hline \multirow{3}{*}{ Gender } & Male & 282 & 41.8 \\
\hline & Female & 393 & 58.2 \\
\hline & Total & 675 & 100 \\
\hline \multirow{5}{*}{ Marital status } & single & 275 & 40.7 \\
\hline & Marriage & 365 & 54.1 \\
\hline & Divorce & 24 & 3.6 \\
\hline & Widowed & 11 & 1.6 \\
\hline & Total & 675 & 100 \\
\hline \multirow{3}{*}{ Children } & Yes & 332 & 49.2 \\
\hline & No & 343 & 50.8 \\
\hline & Total & 675 & 100 \\
\hline \multirow{4}{*}{ Education } & Intermediate and below & 26 & 3.9 \\
\hline & High school & 134 & 19.9 \\
\hline & University & 515 & 76.3 \\
\hline & Total & 675 & 100 \\
\hline \multirow{5}{*}{ Occupation } & Student & 163 & 24.1 \\
\hline & Employee & 319 & 47.3 \\
\hline & Retired & 58 & 8.6 \\
\hline & unemployed & 135 & 20 \\
\hline & Total & 675 & 100 \\
\hline
\end{tabular}

\begin{tabular}{|l|c|c|}
\hline \multicolumn{3}{|c|}{$\begin{array}{c}\text { Table 2: Participants' Awareness } \\
\text { about compulsory Premarital Screenin }\end{array}$} \\
\hline & N & $\%$ \\
\hline Yes & 551 & 81.6 \\
\hline No & 124 & 18.4 \\
\hline Total & $\mathbf{6 7 5}$ & $\mathbf{1 0 0 . 0}$ \\
\hline
\end{tabular}

$N$ : numbers

The vast majority of participants, 645 (95.6\%) thought that carrying out premarital screening is important. Similarly, 651 (96.4\%) agreed to carry out the premarital screening compared to only nine participants $(1.3 \%)$ did not agree to carry out the premarital screening. Lastly, $81.6 \%$ knew about the law of compulsory PMS in Saudi Arabia (Table 2).

Analysis regarding the reasons to carry PMS showed that almost half $(54.5 \%)$ of the participants agreed to take PMS to prevent transmission of disease to their offspring, $22.2 \%$ agree to prevent transmission of infectious diseases to themselves, $14.4 \%$ agree to ensure healthy state of the partner and 5.3\% agree to ensure a healthy fitness for marriage (Figure 1). When asked about the knowledge of the diseases for which tests are done in the premarital screening, $77.2 \%$ and $65.2 \%$ of the participants knew about the inclusion of SCA and $\beta$-thalassemia in PMS, respectively. In addition, $59.4 \%$ and $66.8 \%$ knew that hepatitis and autoimmune deficiency disease (AIDS) are included in the PMS (Table 3).

Results regarding relationship between the agreement of the participants to carry out PMS and the educational level showed that the educational level had a significant impact

$N$ : numbers

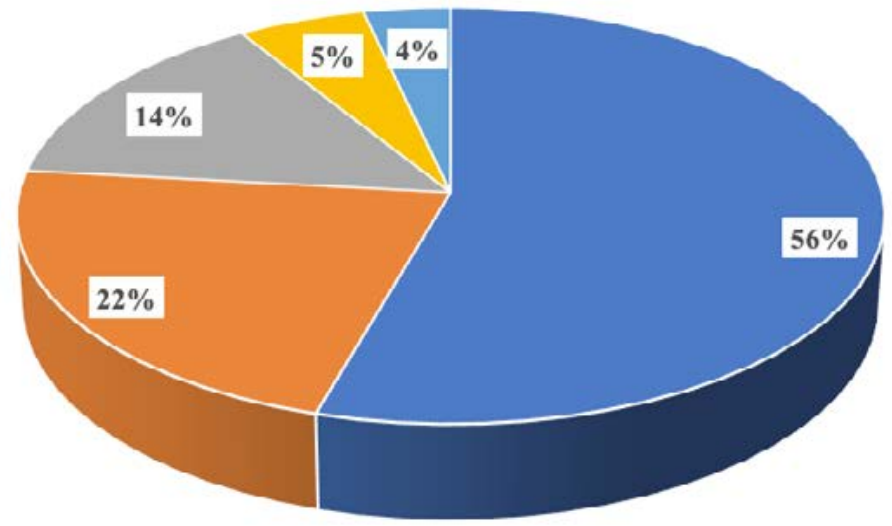

- Prevent transmission of hereditary diseases to offspring

- Prevent transmision of infectious diseases to me

= Ensure healthy state for partner

" Ensure healthy fitness for marriage

- No answer

Figure 1: Reasons for agreement to carry out premarital screening 
Journal of Healthcare Sciences

on the agreement to carry out PMS as the majority of the participants agreed to do PMS were highest among university graduates $(98.1 \%)$ and lowest among intermediate school graduates (80.8\%) (p-value 0.00) (Table 4).

In relation to the attitude towards the possibility of having affected children, approximately half of the participants would not continue the marriage, while $21 \%$ would base their decision on the probability of getting affected children with the diseases, $14.2 \%$ would get married anyway and $(13.8 \%)$ did not know what to do. Females were more likely to cancel the marriage (55.7\%) compared to males $(44.3 \%)$ if there was a possibility of having affected children. Furthermore, $20.6 \%$ of male participants and $9.7 \%$ of female participants would continue the marriage if PMS were positive for SCD or thalassemia (Figure 2).

\begin{tabular}{|l|l|c|c|}
\hline \multicolumn{4}{|c|}{ Table 3: Knowledge about diseases } \\
included in the premarital screening (n=675) \\
\hline \multirow{2}{*}{ SCD } & Yes & N & $\%$ \\
\hline \multirow{2}{*}{ Thalassemia } & No & 521 & 77.2 \\
\hline \multirow{2}{*}{ Hepatitis } & Yes & 154 & 22.8 \\
\hline & No & 440 & 65.2 \\
\hline \multirow{2}{*}{ AIDS } & Yes & 235 & 34.8 \\
\hline & No & 401 & 59.4 \\
\hline & Yes & 274 & 40.6 \\
\hline
\end{tabular}

$N$ : numbers

\begin{tabular}{|c|c|c|c|c|c|c|c|}
\hline & \multicolumn{2}{|c|}{ Intermediate and below } & \multicolumn{2}{|c|}{ High school } & \multicolumn{2}{|c|}{ University } & P-value \\
\hline & $\mathbf{n}$ & $\%$ & n & $\%$ & n & $\%$ & \multirow{5}{*}{$0.000 *$} \\
\hline Agree & 21 & 80.8 & 125 & 93.3 & 505 & 98.1 & \\
\hline Neutral & 1 & 3.8 & 9 & 6.7 & 5 & 1 & \\
\hline Disagree & 4 & 15.4 & 0 & 0 & 5 & 1 & \\
\hline Total & 26 & 100 & 134 & 100 & 515 & 100 & \\
\hline
\end{tabular}

* Chi-square test of statistical significance

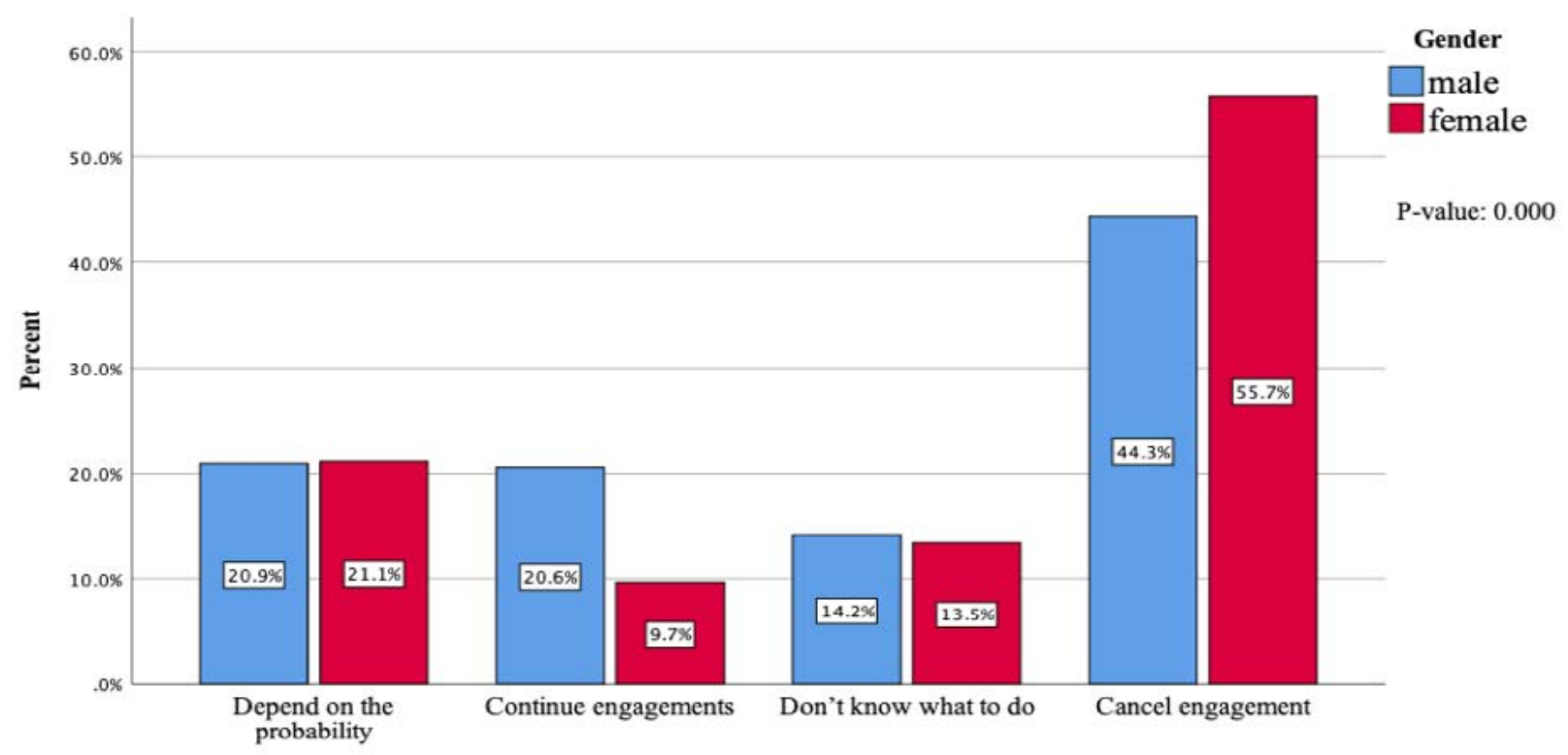

Figure 2: Reasons for agreement to carry out premarital screening 


\section{Journal of Healthcare Sciences}

\section{Discussion:}

This study was conducted to assess knowledge and attitude about pre-marital counselling that is aimed to reduce hereditary diseases in the community. The majority of participants, 645 (95.6\%) thought that carrying out premarital screening (PMS) was important and that among 551 participants, $(81.6 \%)$ knew that PMS is compulsory by law. In comparison, our results was slightly higher in comparison with a study done in Jeddah in 2013 where they found that $93.7 \%$ of the participants had heard about PMS. Having high knowledge of those who knew about PMS could be due to the fact that PMS is compulsory by law in Saudi Arabia and it has been there for many years (4).

Regarding reasons that encourages couples to carry PMS prior to marriage, almost half of the participants (54.5\%) responded that it is necessary to prevent transmission of diseases to their offspring's and $22.2 \%$ responded that it is aimed to prevent transmission of hereditary diseases. Screening timing, socio-religious issues, access to prenatal detection, awareness and counselling affected decisions in similar study. Meanwhile, a study in China among newly married respondents found that factors such as individual perceived benefits, barriers and attitudes were determinants of premarital medical examination decision (5). Another study among public high schools in Oman concluded that the majority of students $(87.4 \%)$ believed that PMS is important, and most students $(87.2 \%)$ indicated that they would undergo this service. These results confirm that perceived risk and benefits are important factors for people to conduct PMS $(6,7)$.

In a study conducted in Al Madinah in Saudi Arabia, participants were asked about the possibility to diagnose sickle cell disease (SCD) and thalassemia by PMS Among 2,554 participants, around two-thirds (61.3\%) of the included population responded with "true" and one-third responded with "I don't know". This is similar to our current study as $440(65.2 \%)$ knew that thalassemia is included in PMS. However, in regard to SCD, the percentage was slightly higher $521(77.2 \%)$, this indicates that the general population know more about SCD than thalassemia. This can be due to the higher prevalence of $\mathrm{SCD}$ in the eastern region in Saudi Arabia $(1,5)$.

In our study we observed that the highest percentage of agreement with PMS was with those with higher education level. Among 515 participants with university education, $505(98.1 \%)$ agreed on carrying PMS. These results are similar with that of a study conducted in 2010 among unmarried female students in King Abdulaziz university in Jeddah, Saudi Arabia which showed that $(99 \%)$ of female students either strongly agreed or agreed on the importance of PMS (8).

A study conducted in 10 public high schools in Muscat, Oman between May and July of 2016 on a total of 1,541 participants asking whether PMS can affect their children, $36.6 \%$ responded to continue the marriage, 10 $\%$ to discontinue the engagement, $6.6 \%$ to proceed with marriage due to emotional reasons, $1.2 \%$ would proceed with marriage due to family pressure and $17.4 \%$ wouldn't know what to do (7). In comparison with our study, 51\% choose to cancel marriage if PMS would affect their offspring, $14.2 \%$ would continue engagement, $13.8 \%$ don't know what to do and $21 \%$ responded that the decision will depend on the probability of getting the disease. In addition, regarding gender attitude towards the possibility to get an affected child, we found that majority of females (55.7\%) and males (44.3\%) would not continue the marriage (9).

Regarding our study limitation, the study was carried only among 3 areas of close proximity cities, which is not reflective of the whole Eastern Region population. Furthermore, two of the largest malls in the region refused to give us permission to conduct the study and we had to get it from other malls nearby. Other variables were not explored such as the effect of educational campaigns from the ministry of health and school education about the importance of PMS.

\section{Conclusion:}

This study revealed that there is very good knowledge about premarital screening. There is a need to increase awareness about sickle cell anemia and thalassemia to raise the number who would cancel the marriage if any of these diseases are found to be positive during premarital screening with the possibility of transmission such diseases to offspring.

\section{Acknowledgments:}

We would like to thank all the malls who allowed us to conduct our study and the participants who took their time to fill in the survey during the study duration.

\section{Disclosure:}

\section{Conflict of interest:}

The authors declared no potential conflicts of interest with respect to the research, authorship, and/or publication of this article. 


\section{Journal of Healthcare Sciences}

\section{Funding:}

None

\section{Ethical Consideration:}

The ethical approval was obtained from the Research and Ethics Committee at the College of Medicine and Medical Sciences at the Arabian Gulf University (AGU). Official permissions to conduct the study were obtained from all the selected malls.

\section{Data Availability:}

The survey used in this paper is attached as a supplementary material.

\section{Author Contribution:}

All authors contributed in data collection, data analysis, writing, drafting, proofreading and finalizing the manuscript.

\section{References:}

1. Memish ZA, Owaidah TM, Saeedi MY. Marked regional variations in the prevalence of sickle cell disease and $\beta$-thalassemia in Saudi Arabia: findings from the premarital screening and genetic counseling program. Journal of epidemiology and global health. 2011;1(1):61-8.

2. AlHamdan NA, AlMazrou YY, AlSwaidi FM, Choudhry AJ. Premarital screening for thalassemia and sickle cell disease in Saudi Arabia. Genetics in Medicine. 2007;9(6):372-7.

3. Hejri Y, Moussa M, Bushran S, Al-Mutairi K, AlHarbi A. Evaluating premarital screening knowledge in Saudi students. Int J Community Med Public Health. 2015;2:540-51.
4. Ibrahim NK, Bashawri J, Al Bar H, Al Ahmadi J, Al Bar A, Qadi M, et al. Premarital Screening and Genetic Counseling program: knowledge, attitude, and satisfaction of attendees of governmental outpatient clinics in Jeddah. Journal of infection and public health. 2013;6(1):41-54.

5. AlQahtani RS, Bedaiwi AA, Alburkani AM, AlFahed MM, Alhoraibi RA, Tarawah AM. Knowledge and response of the community to premarital screening program (Sickle Cell Anemia $\backslash$ Thalassemia); AlMadinah, Saudi Arabia. Journal of Applied Hematology. 2018;9(2):59.

6. Li L, Gu YM, Zhou C, Zhou XD, Zheng WJ, Yang TZ. [Influencing factors on the voluntary premarital medical examination among Chinese population]. Zhonghua liu xing bing xue za zhi = Zhonghua liuxingbingxue zazhi. 2011;32(11):1105-9.

7. Al-Kindi RM, Kannekanti S, Natarajan J, Shakman L, Al-Azri Z, Al-Kalbani NI. Awareness and Attitude Towards the Premarital Screening Programme Among High School Students in Muscat, Oman. Sultan Qaboos Univ Med J. 2019;19(3):e217-e24.

8. Ibrahim NK, Al-Bar H, Al-Fakeeh A, Al Ahmadi J, Qadi M, Al-Bar A, et al. An educational program about premarital screening for unmarried female students in King Abdul-Aziz University, Jeddah. Journal of infection and public health. 2011;4(1):30-40.

9. Al-Farsi OA, Al-Farsi YM, Gupta I, Ouhtit A, AlFarsi KS, Al-Adawi S. A study on knowledge, attitude, and practice towards premarital carrier screening among adults attending primary healthcare centers in a region in Oman. BMC Public Health. 2014;14:380-. 